Webology, Volume 17, Number 1, June, 2020

\begin{tabular}{|l|l|l|l|}
\hline Home & Table of Contents & Titles \& Subject Index & Authors Index \\
\hline
\end{tabular}

\title{
Review of Iranian Journal Articles Indexed in Web of Science Based on Altmetric Indicators in Scientific Social Media
}

\author{
Ameneh Shenavar \\ MSc., Department of Knowledge and Information Science, Faculty of Education and Psychology, Alzahra \\ University, Tehran, Iran. ORCID: 0000-0003-0271-5758. E-mail: amenehshenavar@yahoo.com
}

\begin{abstract}
Abbas Doulani*
*Corresponding Author, Assistant Professor, Department of Knowledge and Information Science, Faculty of Education and Psychology, Alzahra University, Tehran, Iran. ORCID: 0000-0002-6917-0097. E-mail: a.doulani@alzahra.ac.ir
\end{abstract}

Received February 27, 2020; Accepted June 20, 2020

\begin{abstract}
The purpose of this study was to investigate the impact of social media on Iranian articles published in Iranian English-language journals indexed in the Web of Science (WoS) citation database. The present applied research used the survey methodology and scientometric approach based on altmetric indicators. The study population consisted of 124 Iranian English-language journals indexed in Web of Science in 2018. Data were also collected from the Altmetric database and its free "Bookmarklet" tool. Results of the study showed that Iranian journals had relatively low Altmetric coverage and only 417 (9\%) of articles have been posted on social media at least once in 2018, the most important social media distributing Iranian journal articles were Mendeley (94\%), and twitter (81.8\%), respectively. The correlation between altmetric indicators and the citation rate of the examined articles showed a statistically significant, positive relationship between the number of readers of Iranian journal articles in Mendeley and Twitter with the number of citations received in the Web of Science database, so the regression model was significant.
\end{abstract}

\section{Keywords}

Altmetric indicators; Iranian journals; Articles; Web of Science; Social media 


\section{Introduction}

Mass production of information and knowledge dissemination in specialized fields has made it important to study and evaluate information texts. One way to measure the effectiveness and quality of researches is to use a rich and diverse set of Bibliometrics indicators (Mokhtari, Roumiyani \& Saberi, 2019). These metrics range from traditional metrics (publishing counting, journal impact factor, etc.) to new, promising web-based metrics that assess the quality of research (Harnad, 2008). Each of these measures has advantages and disadvantages, and new ones are added every day to complement the previous ones. Citation as the most important indicator and citation analysis are used as a valid and reliable method in evaluating products, however, citation has limitations such as the time required for citation, lack of free access to expensive citation databases such as Thomson Reuters and Scopus, and non-coverage of all types of information sources (Mas-Bleda et al., 2014). On the other hand, with the advent of Web 2.0 and the expansion of social media and its impact on the communication of individuals in different societies and the creation of new links between researchers, the inability of traditional measures to measure these new communications became more apparent (Macroberts \& Macroberts, 2010).

One of the latest evolving metrics is altmetric. It is a combination of the two words alternative and metrics (Galligan \& Dyas-Correia, 2013). In fact, altmetrics or social network metrics are measures that can be used alongside "traditional citation-based metrics" to examine the impact of scientific productions on the social web environment (Priem, Grooth \& Taraborelli, 2012). Altmetrics includes reviews of scholarly work on social media such as Facebook, Twitter, Wikipedia, Blogs, citation management tools like Mendeley, news outlets, and more. The basis of the review in altmetric studies is the paper (article level indicators) but other levels of performance such as individuals, magazines, institutions, and countries can also be addressed (Neylon \& Wu, 2009).

Among the features of altmetrics can be the social impact assessment of research outputs, the study of real-time impact of research outputs, the evaluation of uncited or low-cited articles and ability to investigate a wide variety of types of information sources (Hammarfelt, 2014; Robinson-Garcia, 2014 \& Erfnmanesh, 2017). When interpreting altmetric data, its current limitations, such as the lack of a clear and comprehensive definition, the absence of a normal index, Exposed to data manipulation, and the absence of standard data, must be taken into account (Costas \& Wouters, 2010). It can be said that all of these are influenced by the new and emerging field of research. Currently, the Altmetrics Institute is one of the most important providers of altmetric data, comprising more than seven million articles. This database collects information on the impact of an article on diverse social media and assigns the altmetric score to the article by weighting in on social media scores (Robinson-Garcia, 2014; Ouchi et al., 2019). 
Given the popularity of various societies in recent years towards social media in Establishing scientific communication and disseminating research findings, So far, the use of these media by Iranian researchers has been less studied. On the other hand, the coverage of Altmetric scores for articles published in recent years is higher than in the past, for this reason, this study intends to use the Altmetric score as a social citation measurement tool; evaluate the effectiveness and visibility of Iranian publications articles indexed in Web of Science by 2018 on social media.

\section{Literature Review}

Considering the importance of Altmetric discussion and its capabilities in evaluating research activities, extensive studies have been conducted in international and domestic levels in recent years.

Erfanmanesh (2016) surveys the presence of 563 articles by Iranian researchers in library and information science at the Web of Science Database, indicating that Twitter, Mendeley and Ulike are the most important social media publishers of library and information science articles. There was also a statistically significant positive correlation between the number of readers of library and information science articles in Mendeley and the Ulike site with the number of citations received in the Web of Science database.

Salagejah and Diary (2016) in their research examined the relationship between SNIP (Source Normalized Impact per Paper) citation indexes, ratings of Scimago Magazine, Eigen factor and Impact Factor of medical sciences Journals with Altmetric indicators and they found that between citation indexes except impact factor, there is a correlation with the mean of the Altmetric scores. Ebrahimy, Setareh and HosseinChari (2016) in his research examined the relationship between visibility and storage metrics in social networks (Ulike site, Mendeley, Figshare) with citation index in Scopus, Web of Science, Pubmed Central. The results showed that the visibility and storage measures at Ulike site, Mendeley and Figshare have a positive and significant correlation with the citation index in all databases studied.

Mohammadi and Thelwall (2014) examined the number of articles stored in humanities and social sciences in Mendeley and the correlation between "read" index and theirs citations. In general, the correlation between the "read" index in Mendeley and the rate of citation to social science articles was higher than humanities articles. The findings showed that there exist a medium correlation between Mendeley bookmarks and citation counts in all the investigated disciplines. In another study, Maleki (2015) investigated the presence of Iranian academic papers in Mendeley. The results showed that about 53 percent of the articles were read at least once in Mendeley. The biochemistry and biology fields had the highest number of articles in Mendeley, followed by the social sciences, technology and physical sciences. 
Zahedi, Costas and Wouters (2015) in a study entitled "Do Altmetrics correlate with citations? Extensive comparison of altmetric indicators with citations from a multidisciplinary perspective", examined the relationship between citations and the altmetric indicators, except Mendeley. The results showed that there is a positive but weak correlation between the number of citations and the Altmetric indicators studied. They also, by examining the Altmetrics indicators derived from the Mendeley Impact, identified it as a useful resource for Altmetrics researches and stated that review and research articles were read, shared and tagged more than other types of documents.

Hassan and Gillani (2016) measured the Altmetric indicators using Google Scholar, Twitter, Mendeley, Facebook, Blogs and Wiki in the 2010-2014 period. The results showed that Mendeley, Twitter, and Facebook were the most cited social networks, and Twitter and Mendeley were more influential than Facebook.

Salinas, Garcia and Contreras (2016) examined articles published by four prominent Spanish universities using the Altmetrics method. The results showed that only 36 percent of the published articles had Altmetrics scores and among the articles of the four universities studied, Pompeu Fabra had the highest score in terms of altmetric indicators.

Kolahi and Khazaei (2016) reviewed the top 50 dental articles in 2014 by Altmetrics method. The results showed that most of the obtained Altmetrics scores were related to open access articles and research papers and also the top 50 articles had 69 to 73 Altmetrics scores. Nuredini and Peters (2016) studied the performance of 30 journals in the field of economics and commerce using altmetric indicators. The results showed that Mendeley, Twitter, and news media were the most important social media publishers of research outputs in the journals. Also, in this study, a significant statistical relationship was found between Altmetrics scores and citation of articles in Web of Science.

Some other studies have examined a social media or Altmetrics service provider, some of which are listed below. Twitter (Eysenbach, 2011; Zhao \& wolfram, 2015; Haustein \& et.al, 2014), Research gate (Li \& Thelwall, 2012; Madhusudhan, 2012; Galligan \& Dyas-Correia, 2013; Thelwall \& Kousha, 2014;), Mendeley (Li, Thelwall \& Giustini, 2012).

A review of the records indicates that there is a correlation between the altmetric indicators and citations in most cases. The results of these studies also emphasize that these indicators can be used as a complement to scientific indicators to evaluate research performance and the impact of scientific productions. Given the importance of the topic, the present study seeks to investigate the presence of Iranian journals indexed in the Web of Science (WoS) database various social media web sites, to identify top articles based on altmetric indicators, and the relationship between check out these articles on social media presence and citation performance. The following questions are answered in this study: 
1. How high is the presence of Iranian journal articles in social media?

2. What is the status of Altmetrics scores of Iranian journal articles?

3. Which media are the most important social media publishers of Iranian journals' articles?

4. Is there a significant relationship between the presence of Iranian journals' articles in social media and the citation performance of these articles in the WoS database?

5. Can the presence of Iranian journal articles on social media predict the citations?

\section{Materials and Methods}

This study in term of purpose is practical and the Altmetrics (Social web based metrics) method is used. The statistical population of this study consists of all articles published in international Iranian-English journals indexed in Web of Science up to 2018 with a DOI (Digital Object Identifier). The steps of the research were that, after entering the Web of Science database in the Advanced Search section, the following search strategy was used:

$$
\mathrm{So}=(\text { Journal Title }) \text { AND PY }=(2018)
$$

Also the document type was selected from the search settings to limit the search results to the article. Performing the searches resulted in retrieval of 124 Iranian journals in the database, out of 124 journals, 71 related to the Ministry of Health and Medical Education, 37 related to the Ministry of Science, Research and Technology, and 16 other titles related to other educational institutions. Searching for individual titles and the time periods, 4057 articles for Ministry of Health publications, 3161 articles for Ministry of Science publications, 766 articles for other educational institutions publications were retrieved. All data collected in this study were obtained from the Altmetrics Institute. Because the DOI is needed to use the Altmetrics Institute data, finally, out of the 7984 articles retrieved, only 4711 had DOI that were examined in this study. Note that the information provided by the Altmetrics Institute only includes scientific documents that contains a DOI, PMID (PubMed identifier), arXiv ID (arXiv identifier) or other standard markers.

The altmetric score is an indicator of the amount of attention to a scientific output that is determined by the Altmetric institute and its purpose is to provide an indicator of the amount of attention a scientific production has attracted. In fact, Altmetrics monitors scientific outputs on social media such as news sites, blogs, Twitter, Facebook, Wikipedia, LinkedIn, Academia, ResearchGate, Reddit, Pinterest, and Mendeley. The Altmetrics score is calculated using a weighting algorithm based on three main factors: Citation rate (refers to the number of times an article title has been cited on other pages), source of citations, and author of citations. It is worth noting that in calculating the Altmetrics score, publishing a research output on different social media has a different rating, for example the highest rating related to the news media (weighing 8 ) and the lowest rating related to LinkedIn, Reddit and Facebook (with Weight equals 0.25). In this study, data collection was done using the free Bookmarklet tool available on Altmetric.com. 
As such, all retrieved documents were searched manually and their Altmetrics score was searched, and if any Altmetrics score was obtained, the data associated with each social media was also extracted. Finally, the collected data, including number of articles, article titles, number of citations, altmetric score, and number of journal articles present in each social media, were entered into an Excel file and analyzed for statistical data by the SPSS software version 21.

\section{Results}

This section presents the findings from the data analysis in response to the research questions:

\section{How high is the presence of Iranian journal articles in social media?}

In response to the first question of the survey (the amount of Iranian journals' articles on social media) the data analysis showed that in 124 Iranian journals indexed in this database, 7984 articles were published, of which only 4711 (59\%) were from digital identifier objects. Therefore, their examination was performed with Bookmarklet tool. On the other hand, among the articles with digital object markers, 4294 cases (91.1\%) have not been used, cited, etc. in any of the social media so far. Thus, only 417 Iranian-English-language journal articles (8.9\%) have so far been shared on social media at least once and have the Altmetrics score (see Table 1).

Table1. The prevalence of Iranian English-language journal articles in social media

\begin{tabular}{|c|c|c|c|c|}
\hline Pubs & $\begin{array}{c}\text { No. of } \\
\text { Articles }\end{array}$ & $\begin{array}{c}\text { No. of } \\
\text { citations }\end{array}$ & $\begin{array}{c}\text { Articles with Alt. } \\
\text { Indicators }\end{array}$ & $\begin{array}{c}\text { Articles without } \\
\text { Alt. Indicators }\end{array}$ \\
\hline Medical & 2343 & 3394 & $305(13 \%)$ & 2038 \\
\hline Non Medical & 1778 & 3429 & $66(3.8 \%)$ & 1712 \\
\hline Other educational institutions & 590 & 1428 & $46(7.8 \%)$ & 544 \\
\hline Total & $\mathbf{4 7 1 1}$ & $\mathbf{8 2 5 1}$ & $\mathbf{4 1 7}$ & $\mathbf{4 2 9 4}$ \\
\hline
\end{tabular}

2. What is the status of Altmetrics scores of Iranian journal articles?

In response to the second research question (Status of Altmetrics scores of Iranian journals), the results of the extraction of Iranian journals data showed that the maximum Altmetrics scores of Iranian journals were 164 (Ministry of Health), 14 (Ministry of Science) and It was 14 (Other educational institutions). Also, the highest mean scores of Altmetrics belong to the publications of the Ministry of Health with a mean of 3.04. Table 2 shows the status of Altmetrics scores of Iranian journals by publication using Altmetrics database information.

Table 2. Status of Altmetrics Scores of Iranian Journal Articles by Publication

\begin{tabular}{|c|c|c|c|c|c|c|}
\hline Publication year & \multicolumn{3}{|c|}{ Max Altmetrics score } & \multicolumn{3}{c|}{ Mean Altmetrics score } \\
\hline until 2018 & $\begin{array}{c}\text { Other educational } \\
\text { institutions }\end{array}$ & $\begin{array}{c}\text { Non- } \\
\text { Medical }\end{array}$ & Medical & $\begin{array}{c}\text { Other educational } \\
\text { institutions }\end{array}$ & $\begin{array}{c}\text { Non- } \\
\text { Medical }\end{array}$ & Medical \\
\hline & 14 & 14 & 164 & 2.13 & 2.12 & 3.04 \\
\hline
\end{tabular}

Survey of the prevalence of top articles in Iranian journals on social media shows that "for example" the article has the highest Altmetrics score (164) obtained from an external research in 
the field of medical science with the participation of 5 researchers in Turkey (an International cooperation). Also this article has been shared 192 times on Twitter, 3 times on Facebook and 2 times on video. The article also had 16 readers at Mendeley and received 5 citations at Web of Science. Other surveys show that all of the most frequently cited articles (in social media) have come from research collaborations and none have been compiled individually. The data for the top 10 Iranian articles indexed in the Web of Science database based on the altmetric scores are presented in Tables 3 .

Table 3. Statistics of top 10 Iranian articles indexed in Web of Science based on the altmetric scores

\begin{tabular}{|c|c|c|c|c|c|c|c|c|c|c|c|c|}
\hline 步 & Article title & $\begin{array}{c}\text { First } \\
\text { Author }\end{array}$ & 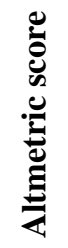 & 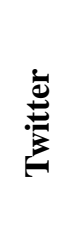 & $\frac{\vec{e}}{\frac{\partial}{0}}$ & $\frac{1}{8}$ & $\frac{\mathscr{6}}{00}$ & 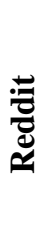 & 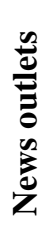 & $\frac{\pi}{8}$ & 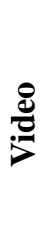 & 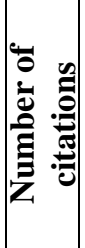 \\
\hline 1 & $\begin{array}{l}\text { Acne located on the trunk, Whey } \\
\text { protein supplementation: Is there } \\
\text { any association? }\end{array}$ & $\begin{array}{l}\text { Fatma } \\
\text { Plein } \\
\text { Cengiz }\end{array}$ & 164 & 192 & 16 & 3 & - & - & - & & 2 & 5 \\
\hline 2 & $\begin{array}{l}\text { Prevalence of sarcopenia in the } \\
\text { world: a systematic review and } \\
\text { meta- analysis of general } \\
\text { population studies. }\end{array}$ & $\begin{array}{c}\text { Gita } \\
\text { Shafiee }\end{array}$ & 23 & 17 & 335 & - & 1 & - & 1 & - & - & 51 \\
\hline 3 & $\begin{array}{c}\text { The effects of ginger on fasting } \\
\text { Blood sugar, hemoglobin A1c, and } \\
\text { lipid profiles in patients with type } 2 \\
\text { diabetes }\end{array}$ & $\begin{array}{l}\text { Motahare } \\
\text { Makhdoo } \\
\text { mi Arzati }\end{array}$ & 22 & 31 & 107 & - & - & - & - & - & 1 & 5 \\
\hline 4 & $\begin{array}{l}\text { Bringing value-based perspectives } \\
\text { to care: including patient and } \\
\text { family members in decision- } \\
\text { making processes }\end{array}$ & $\begin{array}{l}\text { Graeme } \\
\text { Kohler }\end{array}$ & 20 & 30 & 26 & - & - & - & - & - & - & 2 \\
\hline 5 & $\begin{array}{l}\text { Rapid weight loss Vs. slow weight } \\
\text { Loss: which is more effective on } \\
\text { body composition and metabolic } \\
\text { risk factors? }\end{array}$ & $\begin{array}{l}\text { Ashtary } \\
\text { Larkyd }\end{array}$ & 20 & 16 & 31 & 4 & - & - & 1 & - & 3 & 8 \\
\hline 6 & $\begin{array}{l}\text { Environmental factors influencing } \\
\text { the risk of autism }\end{array}$ & $\begin{array}{l}\text { Padideh } \\
\text { Karimi }\end{array}$ & 17 & 22 & 131 & - & - & - & - & - & - & 14 \\
\hline 7 & $\begin{array}{l}\text { Cognitive enhancing of pineapple } \\
\text { extract and juice in scopolamine- } \\
\text { induced amnesia in mice }\end{array}$ & $\begin{array}{l}\text { Amir } \\
\text { Abbas } \\
\text { Momtazi }\end{array}$ & 16 & - & 10 & - & - & - & - & - & - & 1 \\
\hline 8 & $\begin{array}{c}\text { Waste water management and water } \\
\text { quality of river Yamuna in the } \\
\text { megacity of Delhi }\end{array}$ & $\begin{array}{l}\text { Musarat } \\
\text { Parween }\end{array}$ & 14 & 16 & 21 & - & - & - & - & - & - & 3 \\
\hline 9 & $\begin{array}{l}\text { Peruvian mental health reform: A } \\
\text { framework for scaling-up mental } \\
\text { health services }\end{array}$ & $\begin{array}{c}\text { Mauricio } \\
\text { Tayama }\end{array}$ & 13 & 3 & 44 & - & 1 & - & - & - & - & 7 \\
\hline 10 & $\begin{array}{l}\text { Multiple sclerosis gene therapy } \\
\text { with recombinant viral vectors: } \\
\text { Over expression of IL-4, Leukemia } \\
\text { inhibitory factor, and IL-10 in } \\
\text { Wharton's Jelly Stem Cells Used in } \\
\text { EAE Mice model. }\end{array}$ & $\begin{array}{l}\text { Ahmad } \\
\text { Hosseini }\end{array}$ & 12 & 4 & 19 & 1 & 1 & - & - & - & - & 3 \\
\hline
\end{tabular}


Survey of Iranian journals with Altmetrics score indicates that articles published in Journal of Health Policy and Management with a mean Altmetrics score of 3.64, Journal of Diabetes and Metabolic Disorders with average Altmetrics score of 3.5 (Ministry of Health) and Science and technology Journal of Environmental with average Altmetrics score of 2.8 (Ministry of Science) had the highest presence in social media environment. Figure 1 shows the data of the top 10 Iranian journals in terms of Altmetrics score.

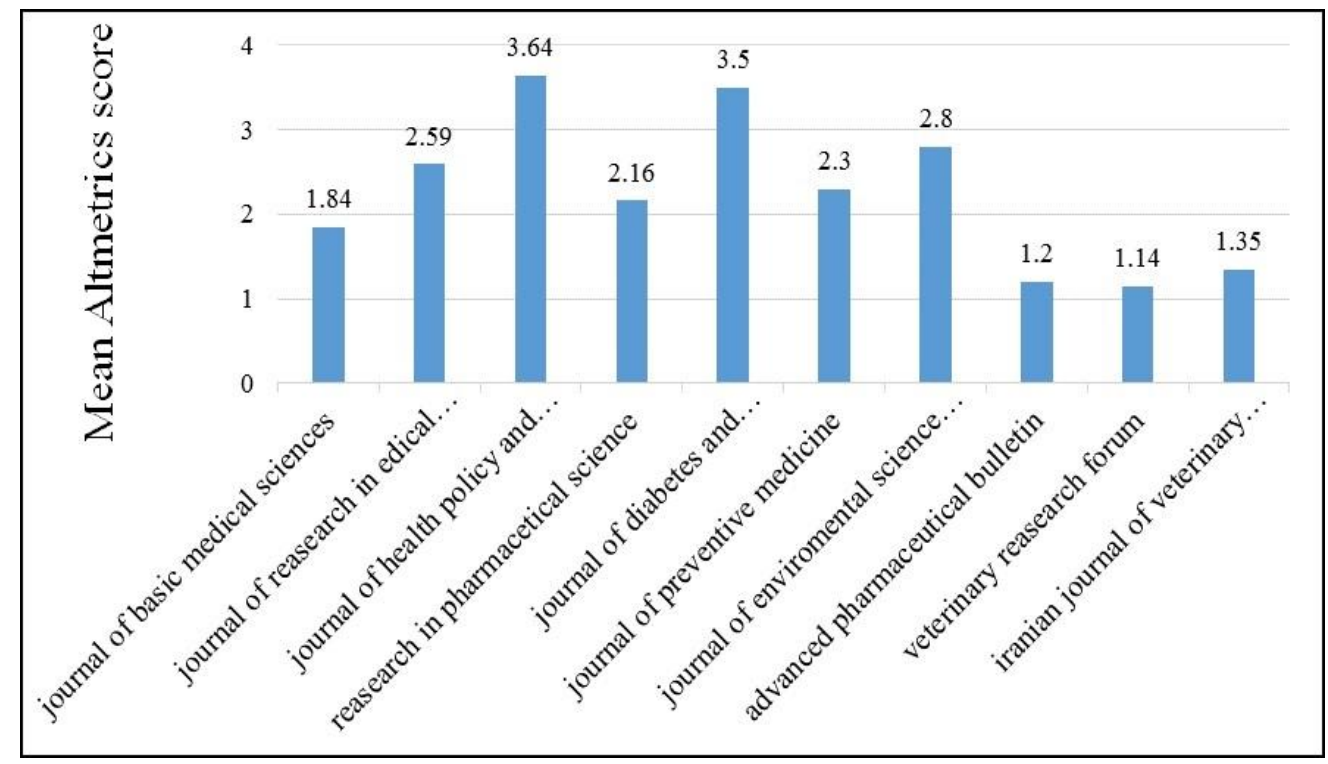

Figure 1. Top ten Iranian journals based on Altmetrics score

\section{Which media are the most important social media publishers of Iranian journals' articles?}

In response to the third research question (the most important social media publisher of Iranian journals), the results of a variety of social media surveys showed that Mendeley, with 392 articles (94\%), was the most important media used by researchers. Wikipedia has the least use among researchers with three articles. Table 4 indicates the amount of articles present in social media by topic of publication. Figure 2 shows that in addition to the social media mentioned, there are other tools that are considered for sharing researcher publications.

Table 4. The prevalence of Iranian journals' articles in social media by subject area of publication

\begin{tabular}{|l|c|c|c|}
\hline \multicolumn{1}{|c|}{ Publications } & $\begin{array}{c}\text { Readership } \\
\text { Mendeley }\end{array}$ & $\begin{array}{c}\text { Readership } \\
\text { Twitter }\end{array}$ & $\begin{array}{c}\text { Post } \\
\text { Facebook }\end{array}$ \\
\hline Medical & 320 & 278 & 38 \\
\hline Non Medical & 27 & 30 & 2 \\
\hline Other educational institutions & 45 & 33 & 5 \\
\hline
\end{tabular}




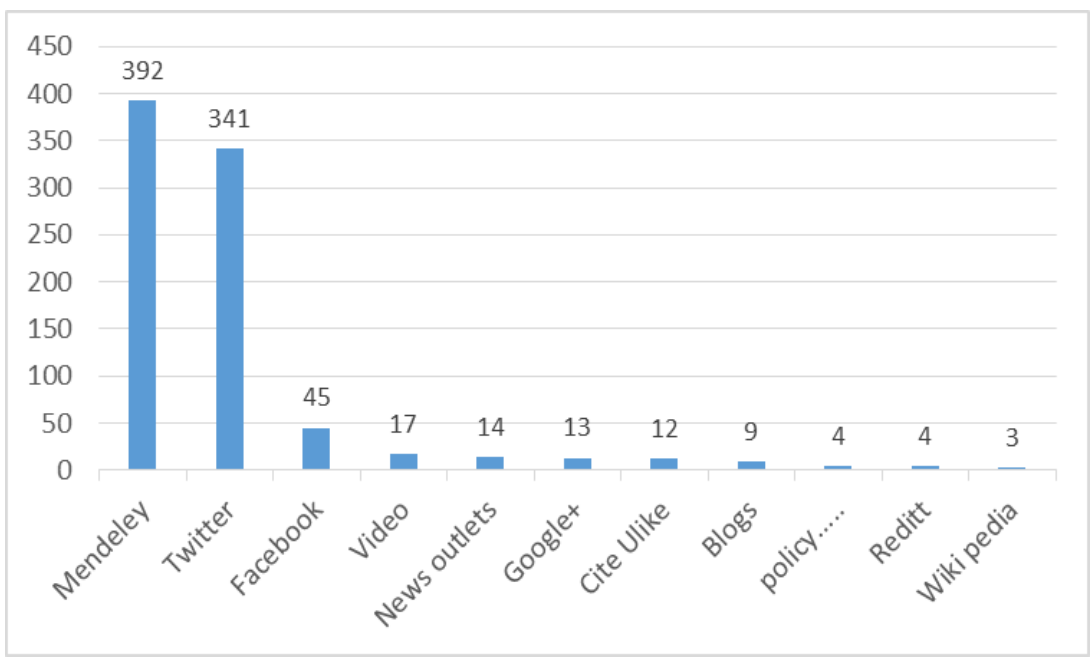

Figure 2. The contribution of different social media in sharing articles with Altmetric score

4. Is there a significant relationship between the presence of Iranian journals' articles in social media and the citation performance of these articles in the Web of Science database?

In response to the fourth research question, to investigate the relationship between the presence of Iranian journals' articles in social media and the citation performance of these articles, used the Spearman's rank correlation test (Due to the non-normal distribution of data in the Kolmogorov-Smirnov test). The results showed a significant and positive correlation between the variables studied.

Table 5. Correlation test results between article citations in Web of Science and their performance in social networks

\begin{tabular}{|c|c|c|c|}
\hline & Altmetrics Score & Readership Mendeley & Readership Twitter \\
\hline $\begin{array}{c}\text { Web of Science } \\
\text { citations }\end{array}$ & P-value 0.009 & 0.000 & 0.050 \\
\hline & $\begin{array}{c}\text { Sperman's rho 0.127 } \\
\text { correlation }\end{array}$ & 0.377 & 0.340 \\
\hline
\end{tabular}

5. Can the presence of Iranian journal articles on social media predict the citations?

Linear regression formula was used to analyze question 5. The results of linear regression test showed that the regression model is significant and the indicator of articles presence in social media can predict the number of citations. The regression model is significant with respect to beta $($ Beta $=0.46)$ and coefficient of explanation $(\mathrm{R} 2=0.49)$. Explanation coefficient indicates that 49 percent of the variance and the citation indicator variations can be predicted by the variable number of articles present on social media. Also according to ANOVA test, there was a significant effect between the number of citations and the amount of articles present in social media $(\mathrm{p}=0.0000)$. This suggests that the presence of articles in social media is able to predict the citations in this study (see Table 6). 
Table 6. Result of Regression analysis

\begin{tabular}{|c|c|c|c|c|c|}
\hline Independent variable & Dependent variable & R square & Beta & T & Sig. \\
\hline Altmetric & Citations & 0.49 & 0.46 & 2.78 & 0.000 \\
\hline
\end{tabular}

\section{Conclusion}

The purpose of this study was to study the presence of Iranian journals indexed in Web of Science in social media environment. The findings of the study showed that out of 4711 Iranian journals indexed in the science database from 2015-2019, only 417 documents (9\%) were shared on 11 different social media at the time of data collection. It can be stated that the presence of only 9 percent of Iranian journals' articles in the social web environment can indicate the relatively limited use of researchers by these media in facilitating scientific interaction. By examining the status of Altmetrics scores of Iranian journals, it can be concluded that all of these articles have been the result of research collaborations and none have been compiled individually. On the other hand overall (73\%) of the articles with altmetric indicators belonged to the medical sciences and nine of the top ten articles (in terms of the altmetric score) were in the medical field. Similar results have also been reported in popular media articles in Erfanmanesh and Hosseini (2017), Erfanmanesh (2016) and Costas, Zahedi and Wouters (2015). The presence of reviewed articles in different types of social media indicates that Mendeley (94\%) and Twitter $(81 / 8 \%)$ have been the most important tools for sharing Iranian journal articles in the social web environment. Costas, Zahedi and Wetheres, (2014); Nordini and Peters, (2016); Erfanmanesh, (2016); Erfanmanesh, and Hosseini, (2017) cite Mendeley and Twitter as top social media researchers.

It should be noted, however, that the value of citing articles in any of the media outlets is not equal. For example, reviewing an article on a blog can be due to its attractiveness, debate, and interpretation of the results of the article, however, the presence of an article in Mendeley, which is actually a citation management system that can be due to the relevance of the article's topic to the topic the user is searching for on Altmetric.com.

The findings indicate a statistically significant, positive and weak correlation between the number of citations of Iranian journals articles and the Altmetrics score of these articles, as well as there are the positive and significant relationship between the number of readers of Iranian journals' articles in Mendeley and Twitter with the number of citations on Web of Science. The results of this study also showed that the regression model was significant and 49 percent of the variation and variance of citation can be predicted by the amount of articles present in social media. The results of this study confirm the results of Sedighi (2019), Erfanmanesh (2017), Mohammadi and Thelwall (2014), and Hastin et al. (2014). Finally, it can be concluded that social media can have a positive impact on the amount of citations to scientific articles. Citation as the most important indicator and citation analysis are used as a reliable method of measuring 
production (Imani, Mirezati \& Saberi, 2019). Therefore, researchers can use social media to better search for information as well as increase their citation of their scientific activities. Therefore, it is suggested that scholars and researchers sharing their work on social media not only provide users with access to scientific publications but also increase the number of readers and ultimately increase the effectiveness and citation of scientific works.

\section{References}

Bakhshi, S. I., \& Gutam, S. (2013, December). Scholarly Communication through Social Networks: A Study. In International Conference on Asian Digital Libraries (pp. 178-179). Springer, Cham.

Costas, R., Zahedi, Z., \& Wouters, P. (2015). Do "altmetrics" correlate with citations? Extensive comparison of altmetric indicators with citations from a multidisciplinary perspective. Journal of the Association for Information Science and Technology, 66(10), 2003-2019.

Ebrahimy, S., Setareh, F., \& HosseinChari, M. (2016). Assessing the relationship between the alternative metrics of visibility and social bookmarking with citation index in PLOS Altmetrics. Iranian Journal of Information Processing and Management, 31(3), 693-693.

Erfanmanesh, M. (2017). The presence of Iranian Information science and library science articles in social media: an altmetric study. Iranian Journal of Information processing and Management, 32(2), 349-373.

Erfanmanesh, M. A., \& Hoseini, E. (2017). Dissemination of the Iran's international scientific output in social media.

Eysenbach, G. (2011). Can tweets predict citations? Metrics of social impact based on Twitter and correlation with traditional metrics of scientific impact. Journal of medical Internet research, 13(4), e123. Retrieved January 15, 2020, from https://asset.jmir.pub/assets/4a97f28db2792d6e07f13d975186bf.pdf.

Galligan, F., \& Dyas-Correia, S. (2013). Altmetrics: rethinking the way we measure. Serials review, 39(1), 56-61. $\quad$ Retrieved January 15, 2020, from https://www.sciencedirect.com/science/article/abs/pii/S009879131300004X

Hammarfelt, B. (2014). Using altmetrics for assessing research impact in the humanities. Scientometrics, 101(2), 1419-1430.

Harnad, S. (2008). Validating research performance metrics against peer rankings. Ethics in science and environmental politics, 8(1), 103-10.

Hassan, S.-U., \& Gillani, U. A. (2016). Altmetrics of" altmetrics" using Google Scholar, Twitter, Mendeley, Facebook, Google-plus, CiteULike, Blogs and Wiki. arXiv preprint arXiv:1603.07992.

Haustein, S., Peters, I., Sugimoto, C. R., Thelwall, M., \& Larivière, V. (2014). Tweeting biomedicine: An analysis of tweets and citations in the biomedical literature. Journal of the Association for Information Science and Technology, 65(4), 656-669. 
Holmberg, K. J. (2015). Altmetrics for information professionals: Past, present and future: Chandos Publishing.

Imani, B., Mirezati, S. Z., \& Saberi, M. K. (2019). A Bibliometric Analysis of International Journal of Nursing Studies (1963-2018). Library Philosophy and Practice, 2019 (2677), 1-14.

Kolahi, J., \& Khazaei, S. (2016). Altmetric: Top 50 dental articles in 2014. British dental journal, 220(11), 569.

Li, X., \& Thelwall, M. (2012). F1000, Mendeley and traditional bibliometric indicators. Paper presented at the Proceedings of the 17th International Conference on Science and Technology Indicators.

Li, X., Thelwall, M., \& Giustini, D. (2012). Validating online reference managers for scholarly impact measurement. Scientometrics, 91(2), 461-471.

MacRoberts, M. H., \& MacRoberts, B. R. (2010). Problems of citation analysis: A study of uncited and seldom-cited influences. Journal of the American Society for Information Science and Technology, 61(1), 1-12.

Madhusudhan, M. (2012). Use of social networking sites by research scholars of the University of Delhi: A study. The International Information \& Library Review, 44(2), 100-113.

Maflahi, N., \& Thelwall, M. (2016). When are readership counts as useful as citation counts? Scopus versus Mendeley for LIS journals. Journal of the Association for Information Science and Technology, 67(1), 191-199.

Maleki, A. (2015). Mendeley readership impact of academic articles of Iran. Paper presented at the ISSI.

Mas-Bleda, A., Thelwall, M., Kousha, K., \& Aguillo, I. F. (2014). Do highly cited researchers successfully use the social web? Scientometrics, 101(1), 337-356.

Mohammadi, E., \& Thelwall, M. (2014). Mendeley readership altmetrics for the social sciences and humanities: Research evaluation and knowledge flows. Journal of the Association for Information Science and Technology, 65(8), 1627-1638.

Mokhtari, H., Roumiyani, A., \& Saberi, M. K. (2019). Bibliometric analysis and visualization of the Journal of Artificial Societies and Social Simulation (JASSS) between 2000 and 2018. Webology, 16(1), 166-183.

Nemati-Anaraki, L., Aghajani-Koupaei, H., \& Alibeyk, M. (2018). The impact of Iranian pediatrics articles based on Altmetric method: 2010-2016. Journal of Health Administration (JHA), 20(70).

Neylon, C., \& Wu, S. (2009). Level metrics and the evolution of scientific impact. PLoS biology, $7(11), \mathrm{e} 1000242$. 
Nuredini, K., \& Peters, I. (2016). Enriching the knowledge of altmetrics studies by exploring social media metrics for Economic and Business Studies journals. Paper presented at the Proceedings of the 21st International Conference on Science and Technology Indicators (STI Conference 2016), València (Spain), September 14-16, 2016.

Ouchi, A., Saberi, M., Ansari, N., Hashempour, L., \& Isfandyari-Moghaddam, A. (2019). Do altmetrics correlate with citations? A study based on the 1,000 most-cited articles, Information Discovery and Delivery, 47(4), 192-202.

Priem, J., Groth, P., \& Taraborelli, D. (2012). The altmetrics collection. PloS one, 7(11), e48753.

Robinson-García, N., Torres-Salinas, D., Zahedi, Z., \& Costas, R. (2014). New data, new possibilities: exploring the insides of Altmetric.com. arXiv preprint arXiv:1408.0135.

Salajegheh, M., \& Diari, S. (2016). The relationship between altmetrics and SNIP, SJR, Eigenfactor and IF of medical science journals. Journal of National Studies on Librarianship and Information Organization, 27(2), 167-81.

Sedighi, M. (2019). The Role of Social Media in Assessing the Impact of Research (Case Study: The Field of Scientometrics). Iranian Journal of Information processing and Management, 34(2), 765-792.

Thelwall, M., \& Kousha, K. (2014). Academia.edu: Social network or academic Network? Journal of the Association for Information Science and Technology, 65(4), 721-731.

Torres-Salinas, D., Robinson-García, N., \& Jiménez-Contreras, E. (2016). Can we use altmetrics at the institutional level? A case study analysing the coverage by research areas of four Spanish universities. arXiv preprint arXiv:1606.00232.

Wouters, P., \& Costas, R. (2012). Users, narcissism and control: tracking the impact of scholarly publications in the 21st century: SURF Foundation Utrecht.

Zhao, Y., \& Wolfram, D. (2015). Assessing the popularity of the top-tier journals in the LIS field on Twitter. Paper presented at the Proceedings of the 78th ASIS\&T Annual Meeting: Information Science with Impact: Research in and for the Community.

\section{Bibliographic information of this paper for citing:}

Shenavar, A., \& Doulani, A. (2020). "Review of Iranian journal articles indexed in Web of Science based on altmetric indicators in scientific social media." Webology, 17(1), Article 214.

Available at: http://www.webology.org/2020/v17n1/a214.pdf

Copyright (C) 2020, Ameneh Shenavar and Abbas Doulani. 